\title{
The Impact of Human Capital on income-Based on the Perspective of Education
}

\author{
Li Bingshui ${ }^{\mathrm{a} 1}$, Hu Hong-wei ${ }^{\mathrm{a} 2}$, Yan Ya ${ }^{\mathrm{a} 3}$ \\ ${ }^{a}$ Humanities and Social Sciences Department of North China Electric Power University, Baoding, Heibei \\ 071003
}

\begin{abstract}
Human capital, scocial capital and employment type are the main factors which affect labour income, and the differentiation of labour income is based on these factors. This paper, from the basic theory of human capital ,social capital and employment, through the manipulating of these factors, based on a experiential method, tests the significant factors affecting labour income. And we finds that human capital and employment type has positive effect on migrants' labour income, while social capital has no prominent effect on migrant farmers' labour income. Based on the deep analysis, this paper brings forward some advice to advance migrant farmers' labour income based on the perspective of education.
\end{abstract}

Index Terms: Human Capital;Educationl; Empolyment Type; Labour Income.

(C) 2012 Published by MECS Publisher. Selection and/or peer review under responsibility of the International Conference on E-Business System and Education Technology

\section{Introduction}

China's reform and opening-up is the greatest historical process since the 1980s. With economic, social, political and all fields' fierce reforming and profound transformation, In rural China ,hundreds of millions rural labor fiow to urban, this is a unique phenomenon in the process of China's reform. According to statistics, there are 150 million -200 million rural surplus labor in rural China, the absolute number accounts for $1 / 3$ or more in the total rural labor force. According to $\mathrm{Hu}$ Xiaoyi (2007), there were about 2 million people who were out in situ or transferred in the existing labor force in rural China [1].

Labor mobility and income distribution is the perpetual topic in development economics, Lewis's labor unlimited supply theory and the subsequent improvement, Todaro's migration and Schultz's analysis of the transformation of traditional agriculture are clearly expressing the relationship between the labor mobility and income distribution. Previous research and experience shows that rural labors transfer from agriculture to non-agricultural industries to seeking employment, their labor income will be affected by such as age, marriage, education level, geography, migrant working time and other factors[2]. Sen (1967) also shows that rural labor

\footnotetext{
* Corresponding author.

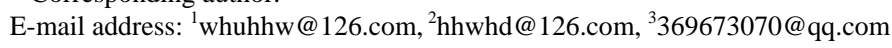


from agriculture to non-agricultural land is not at will, but under the influence of several factors to reduce agricultural production selectivly, and this result does not necessarily affect agricultural production[3]. Hare (1999) research the status of Chinese emigration and migration time, finding the personal characteristics of migration decision-making, lastly thinking that gender, age, marital assets and the average per person holds the propert affect migration obviously, the gender and age are positive correlation, the other two are negative correlation. Meng (2001) considers that the returns to education of rural residents higher than urban residents, vocational training is more important to urban residents, the income gap between urban and rural residents is from discrimination in a large extent. Wu etc (2003) do the empirical analysis in internal migration and between regions in China, holds that the labor-intensive industrial policy and the development of non-agricultural industries have a huge role in promoting the decision-making of rural labor's transer[4]. Johnson (2001)even clearly point that in the process of China's reform and opening up, the reasons for the disparity expansion between urban and rural areas' are limiting the labor free movement from rural and urban areas and the three major different factors between human capital and physical capital investment.

\section{MODELS}

\section{A Variables and data}

The survey used Lamination random sampling method, mainly for migrant farmers living in Wuhan city, including the employment of migrant workers,freedom of small business vendors and private owners. Meanwhile, we note the general equilibrium distribution in age, education level, income level, trades and other aspects to make the survey sample more representative. The survey was Zhongnan University of Economics and Law who organized 130 students taking nearly two months to complete in the summer of 2005. A total of 1200 questionnaires were sent, 1092 were recovered, in which 782questionnaires were effective.

According to research needs, 10 variables were selected into the Multinomial Logistic regression analysis, see Table 1

\section{TABLE 1 VARIBALE SELECTION AND TYPE}

\begin{tabular}{|l|c|}
\hline Dependent variable & Monthy income of labour \\
\hline Independent variable & $\begin{array}{c}\text { gender, age, cultural level, migration time, marriage, source, } \\
\text { employment unit nature, profession nature, employment nature }\end{array}$ \\
\hline
\end{tabular}

B Regression Analysis of Migrant Labor Income.

In this section, this study used Multinomial Logistic (Multinomial logistic regression of variables) methods to analyze the related relationship between migrant labor income, human capital and employment nature , the analog equation is $y=\beta_{\mathrm{i}} \mathrm{x}_{\mathrm{i}}+\varepsilon$, in which, $y$ is migrant monthly income; $\mathrm{x}_{\mathrm{i}}$ is the operation variable of migrant human capital, employment nature and other indicators.

The cumulative distribution is assumed for the Logistic distribution, the model fitting, testing results showed in Table 2, Table 3 
TABLE2 MODEL COMPATIBLE EXMINATION

\begin{tabular}{|c|l|l|l|l|}
\hline Model & -2LogLikelihood & Chi-Square & df & Sig. \\
\hline InterceptOnly & 1535.05 & - & - & - \\
\hline Final & 1324.39 & 210.66 & 80.00 & 0.00 \\
\hline
\end{tabular}

Cox and Snell R2=0.24, Nagelkerke R2 $=0.26$

\section{TABLE3 DEVIATION REGRESSION COEFFICIENT AND EXAMINATION}

Effect

$\begin{array}{cc} & -2 \text { Log Likelihood of Reduced Model } \\ \text { Intercept } & 1324.39 \\ \text { gender } & 1337.04 \\ \text { age cohorts } & 1368.19 \\ \text { culture } & 1370.51 \\ \text { marriage } & 1336.01 \\ \text { source } & 1331.65 \\ \text { Migration time } & 1346.44 \\ \text { cohorts } & 1339.79 \\ \text { employment } & 1338.23 \\ \text { unit nature } & 1329.07 \\ \text { profession } & \\ \text { employment } & \end{array}$

\section{Likelihood Ratio Tests}

Chi-Squa

re $\quad$ Sig.

$0.00 \quad 0 \quad-$

$\begin{array}{lll}12.65 & 4 & 0.01\end{array}$

$43.81 \quad 16 \quad 0.00$

$46.12 \quad 16 \quad 0.00$

$\begin{array}{lll}11.62 & 4 & 0.02\end{array}$

$\begin{array}{lll}7.27 & 4 & 0.12\end{array}$

$22.06 \quad 24 \quad 0.58$

$\begin{array}{lll}15.40 \quad & 4 & 0.00\end{array}$

$\begin{array}{lll}13.84 & 4 & 0.01\end{array}$

$\begin{array}{lll}4.69 & 4 & 0.32\end{array}$

According to the regression results in Table 3, labor income mainly affectes by gender, age, culture, employment unit nature, practitioners way and marriage.

\section{EMPIRICAL ANALYSIS}

\section{A Analysis}

First, it proves that the manpower capital of migrant labor force have a positive effect on their income. Overall, the higher the educational level of farmers into the city, the stronger the ability to work (the older the young adults labor force in their labor age,the longer time they go out and do a part-time job), the higher the income level of male than female migrant farmers higher income more likely. Assumptions of this study failed to prove "the more experience (the longer the migrant workers), the higher labor income" hypothesis, which is worth further studying.

Second, it can not well verify the social capital of migrant labor income positive influence, but got to the examination of the marriage and the source ground direction contrary conclusion. Study found that marriage have significant impact on the income of the migrant labor force, married migrant has the possibility of higher 
income. While the source of labor had no significant effect on labor income.

Third, it basically proved that assumption 3, the employment significantly affects the level of migrant labor income, the nature of the employment units, employment, industry and the nature of employment tends to more "stable", migrant labor income may be higher.

\section{B Reflections}

Based on the above analysis, we believe we can improve institution building and policy development from the following aspects to improve the income level of migrant:

1) Establish an efficient, coherent, practical mobile workforce training system. We must note that the current flow of the labor force (particularly the migrants) are in a lower educational level, lower level of expertise, so do the adaptive position and professional plasticity. How to improve the existing labor force's culture, skill levels, and to enhance their human capital, the establishment of an efficient, coherent, very practical system of labor training is obviously necessary. The effect of the establishment of training system can be examined by various types of technical qualification certification, with the actual needs of the market and close integration of enterprises ,the sustainability of security training ,to meet the need that enhance migrants' human capital continually[5].

2) The establishment of rational and orderly flow of labor employment guidance and job security mechanism.In an ideal labor market, labor have full information and enjoy full freedom to choose in order to achieve reasonable flow and employment. However, in reality, due to the inadequacy of information and other factors, the decision-making can not be optimal when labor mobility due to the interference of various factors. At present, the migrant flows and career blindness, non-rational choice is to explain the reality of this phenomenon. Therefore, the government and society should first to establish fast, efficient and low labor market supply and demand information, play the role of workforce intermediaries actively, and gradually regulate their behavior. [6] Furthermore, it should encourage employers and intermediaries to use the network actively, mobile video and other new technical means of releasing labor supply and demand information. Second, promote the legitimate labor force employment and stable employment. Reasonable and effective legal norms are making up market failures, reducing operating cost of labor markets, protecting the rights and welfare of workers important complement system. Should be the new "Labor Contract Law" as an opportunity to vigorously promote the flow of labor force of legal process, promote the standardization and stability of employment, strengthen the labor and employment law in regulating behavior, protect the workers' right and welfare.

3) Strengthen migrant workers' relationship between the genetic and geographical contact, enhance social capital content. As shown by our results, reflected in personal relationships, social networks, trust relationships and other aspects of social capital have a major hidden role to migrant farmers who are in search of work and likely to increase migrant labor income. Therefore, we should actively encourage migrant populations to enhance genetic, geographical links between social capital to enhance its content. This will not only help reduce the job search process to collect, filter information, employment costs, but also under their relatives, with the assistance of geographical to access to jobs more easily, and even more employment support and business funding.

4) Vigorously strengthen the social protection of migrant workers and the rural social security system. Social security of migrant workers and two security Social Security System is the important protection mechanism for building a new socialist countryside and a socialist harmonious society, it is also the key initiatives to establish urban and rural social security system covering[7]. Should be strengthened social protection of migrant workers and the rural social security system for migrant workers, providing various welfare programs for migrangt farmers convert to citizens.Meanwhile, through the rural social security system, effective co-ordination with rural compulsory education and technical education process, guarantee and 
enhance the human capital fundamentally, remain the basis of rural conditions for promoting mobility labors' income and staying rural farmers' income.

\section{CONCLUSIONS}

Through the theoretical and empirical analysis,we can find that greatly enhance the human capital of migrant labors, raise their level of education, strengthen their professional and technical training is the only way to increase their employment opportunities, to increase their income and to promote their citizenship. Therefore, we must increase the basic education and the technical education in rural areas, we also should give more support to buliding vocational training system.

We can put great efforts to strengthen rural basic education and technical education. Education foundation is the most basic and important institutional system to enhance the the rural labors' human capital, and it is the necessary choice to enhance human capital efficiently and cheap. Education foundation has significant positive externalities ${ }^{[7]}$. The country should increase the intensity of compulsory education policy's advocacy and implementation, increase the investment in basic education in rural areas, transform school and hardware facilities. Through introducing personnel and intensive training ways to improve teacher quality, and improve software and hardware conditions of basic education in rural areas, which lay the foundation for increasing the human capital of migrant labor.Technical and vocational education are the most important part of the education system at present and the future. As the global manufacturing are transferring to China and China's internal manufacturing development and phase shift, the rural migrants who have good professional quality and skills will be the main workforce in China's urban workforce marketplace. As the important connection between basic education and the labor market, the state should increase policy support and capital investment, and guide the community funds to enter to the country actively, making it the main channel of increasing human capita of young labor force in rural areas.

\section{REFERENCE}

[1] Du Jie and Nazneen Kanji,2003. Gender Equality and Poverty Reduction in China: Issues for Development Policy and Practice. Beijing: China Office, the Department for International Development. (in Chinese)

[2] HuaPing,2004. "Uraban Poverty among Young Migrants in China",in: Together with Migrants. Beijing: UNESCO Office Beijing. (In Chinese)

[3] Todaro,M.P.(1969), "A Model of Labor Migration and Urban Unemployment in Less Developmed Countries", America Economic Review,Vol.59, No.1.

[4] Zhao,Yaohui(1999), "Leaving the Countryside: Rural-to-Urban Migration Decisions in China," America Economy Review,89,2 May.

[5] Zhang,Linxiu, Scott Rozelle, and Huang Jikun(2002), "Employment, Recession, and the Role of Education in China's Rural Economy," China Economy Review, Dec., Vol.13 Issue 4. (in Chinese)

[6] Harris,J. and M.Todaro(1970), "Migration, Unemployment and Development: A Two Sector Analysis," America Economics Review, Vol.60, pp.126-142.

[7] World Bank(1997), Sharing Rising Incomes: Disparities in China, Washington.D.C.: World Bank. 